\title{
Indian Aviation Sector: As a Growing Service Sector in Indian Economy
}

\author{
Anuradha Yadav, M.Com., M.Phil, MBA \\ Assistant Professor, Bhagini Nivedita College, University of Delhi, Delhi
}

\begin{abstract}
The problem of this research project is to find out whether Airlines has superior services than all other sectors in India. It should answer the questions about the services of airlines. The Indian aviation industry is one of the most talked about aviation industries in the world. The major reason behind this interest is its liberalisation. After the latter move, Indian airline passengers began enjoying the benefit of choice because Indian carriers quadrupled in number. As if that was not enough, the country recorded a twenty two percent increase in passenger traffic. (Gramaticas, 2007). In the past, the Indian aviation industry was state owned. This meant that airline carriers could not operate under the laws of the free market. Consequently, the government decided to liberalise this industry by encouraging privately owned airlines to join this lucrative sector. The industry has registered a high entry of numerous low cost airline providers. Only twenty five percent of the domestic market shares belong to government owned companies. The other percentage is by private airlines.
\end{abstract}

Keywords: Indian Aviation Industry, Airlines, liberalisation, Sectors, domestic airlines, customer satisfaction, growth

\section{Introduction}

The Indian aviation industry has undergone a rigorous transformation as it is a far cry from what it was in the short term. Previous research with regard to this topic has looked at the successes of the Indian aviation industry after liberalisation. However, there are still minimal discussions about some of the problems plaguing the industry currently. Additionally, there are also few predictions about the future of this industry i.e. can India continue with the momentum that it had started with after liberalisation. This means that there is need for an examination into the likely problems that could slow down this growth or halt it altogether. It should be noted that this current success may simply be an indication of overall momentum within the sector. New players in the market have not yet stabilised and there may be some unforeseen problems in the future. The research studies about the Indian aviation industries situational factors with that of the US aviation sector in order to determine level of liberalisation. We try to examine problems facing the industry today and how these can reflect on the future problems in this research. It helps in assess whether Indian population and infrastructure is capable of handling such rapid expansion. The overall objective of the study will be measured over a period of ten years i.e. whether the Indian aviation industry can sustain its growth over the next ten years.

\section{Objectives}

- To study the customer satisfaction level for the various services provided by the airlines.

- To find out the effectiveness of the services provided by airlines in respect of other sectors.

- To find the preference of customers of airlines.

- To assess whether the Indian aviation industry has the ability to sustain its growth rates in the near future.

- To compare the Indian aviation industries situational factors with that of the US aviation sector in order to determine level of liberalisation.
- To examine problems facing the industry today and how these can reflect on the future problems

- To assess whether Indian population and infrastructure is capable of handling such rapid expansion

\section{Literature Review}

The scope of study of this project is narrow. It mainly focused on some airlines under the aviation industry. The survey was conducted in the areas of Delhi and it was filled in by: Students, working professionals, business, others. The airline industry is painstakingly demanding with regard to capital investments. There is a need to assess Indian readiness for these airline expansions. Airlines is one of the largest and most widespread sector of the country providing its services not only in India as well as outside India also. It has alliance with many other sectors. Airlines offers world class services to the customer at a nominal rate. The national carrier takes immense pride in having successfully played a pivotal role in making various facets of India popular with the people of the world and acting as the country's cultural ambassador. The airline uses the services of one of the advanced plans been operated in the world. The Indian Aviation Industry promises huge growth potential due to large and growing middle class population, favourable demographics, rapid economic growth, higher disposable incomes, rising aspiration of the middle class, and overall low penetration level (less than 3\%). Previous research with regard to this topic has looked at the successes of the Indian aviation industry after liberalisation. However, there are still minimal discussions about some of the problems plaguing the industry currently. Additionally, there are also few predictions about the future of this industry i.e. can India continue with the momentum that it had started with after liberalisation. The passengers towards service qualities in domestic airline industries and SERVQUAL method have been analysed as the third objective. The passengers have accounts in Spice Jet, Indigo, Air India, Jet Airways based on age, gender, marital status, income and other social economic status have been used as chi-square have been applied appropriately. 


\section{International Journal of Science and Research (IJSR) \\ ISSN (Online): 2319-7064}

Index Copernicus Value (2013): 6.14 | Impact Factor (2014): 5.611

The various service quality measures adopted by the domestic airline passenger have been analysed by using Chisquare test have been applied to identify the results underlying five key dimensions from the 10 variable given in the questionnaire.

\section{Methodology}

Objective number one can be done by assessing some of the major indicators of success (such as traffic rights of airline carriers, degree of multiple carrier designation, number of destinations from India to the rest of the world, level of code hire operations, quality of cargo services and type of aircrafts used) against the backdrop of another successful aviation industry. This measurement will mainly be done through secondary research where aviation data for the US and also India will be compared. This method was chosen because it would be difficult to get a summary of a country aviation industry from a specific airline or individual. Consequently, using a summary of the facts would yield more reliable results.(Centre for Management research, 2007) The second specific objective will be measured by assessing the operational environment in India. It should be noted that this current success may simply be an indication of overall momentum within the sector. New players in the market have not yet stabilised and there may be some unforeseen problems in the future. The third objective is with regard to Infrastructural requirements. The airline industry is painstakingly demanding with regard to capital investments. There is a need to assess Indian readiness for these airline expansions. The latter two objectives measured through interviews for major Airline carriers in India. They are at a position to assess Indian current situation. Besides that, it was also assess some closely related industries that act as the aviation industries supplier.

Sample Size: Sample size means the number of people to be surveyed or included in the research project. In this project two hundred and fifty individuals were sampled.

Sampling Unit -Sampling unit is the unit used for sampling. The population should be divisible into a finite number of distinct, non-overlapping units, so that each member of the population belongs to only one sampling unit. In this study sampling units are students, working professionals, business and others. They were sampled throughout Delhi.

Sampling Frame-Sample Frame are those individuals or organizations from which one selects the actual sample for the survey. Ideally, the sample frame is the same as the target population. For this project the sample frame was the population of Delhi ages 18 to 55 .

Sample design: Doing research via sampling was important because of impossibility of finding all of a population, as well as other restrictive parameters like cost, time etc. Our sampling decision should be in-coordination with the research and data objectives. The method opted for taking samples was 'Non-probability sampling'. It was a 'Purposive Non-probability sampling/ Judgement Sampling' was used. The key assumption underlined this type of sampling is that, with sound judgement or expertise, and an appropriate strategy, one can carefully and consciously choose the elements to be included in the sample, so that samples can be developed that are suitable for one's needs. My objective for using 'Judgement Sampling' was that since airline travel is not experienced by everybody, so 'Judgement Sampling' was a must to get the closest and the correct response.

\section{Sample Size: -250 passengers/ respondents}

Method of Data Collection:-Survey/ Personal Contact Method:- In a survey, the researcher carries out opinion polls involving customers, sales persons, dealers, traders and experts. In the survey, the main method of interviewing was by Personal Interviews, as this gave me a better understanding of the needs and preferences of the passenger. Most of the data is quantitative in nature and supported by qualitative data. Instruments for data collection: -The research instruments used for this survey were structured questionnaires. The questionnaires were designed to find the satisfaction levels of Domestic Airlines.

\section{Selection of sample passengers}

Selected domestic airline industry in Delhi and the sample size was determined.

The 250 respondents have been selected proportionately from domestic airline industry passenger population.

\section{Sample of Domestic Airline Passenger}

\begin{tabular}{|c|c|c|c|}
\hline S.No. & Domestic airline & $\begin{array}{c}\text { No. of sample } \\
\text { customers }\end{array}$ & Percentage \\
\hline 1 & Spice Jet & 60 & 24 \\
\hline 2 & Indigo & 80 & 32 \\
\hline 3 & Air India & 70 & 28 \\
\hline 4 & Jet Airways & 40 & 16 \\
\hline & Total & $\mathbf{2 5 0}$ & $\mathbf{1 0 0 . 0 0}$ \\
\hline
\end{tabular}

The sample passengers were selected randomly from the domestic airline industries in which the interview schedule was administered selection of sample airline employee. Simple random sampling technique has been used to select the sample airline employee respondents for the study. Totally 250 respondents from domestic airline passenger in Delhi have been identified.

\section{Results and Discussions}

After the survey done it was found that the critical value was higher than the table value and thus we reject the null hypothesis and accept the alternative hypothesis, which states that airlines has superior and better services than all other sectors India Type I error, also known as an "error of the first kind", an $\alpha$ error, or a "false positive": the error of rejecting a null hypothesis when it is actually true. Plainly speaking, it occurs when we are observing a difference when in truth there is none, thus indicating a test of poor specificity.

\section{Limitation of Study}

The limitations of the research for working airlines with regards to customer satisfaction are as follows: The research

\section{Volume 4 Issue 11, November 2015}




\section{International Journal of Science and Research (IJSR) \\ ISSN (Online): 2319-7064}

Index Copernicus Value (2013): 6.14 | Impact Factor (2014): 5.611

study is limited to the geographical boundaries of Delhi. Only some airlines brand is considered in the research. The study undertaken is sufficiently broad in outlook and wider in coverage as regards the subject matter. All necessary care has been taken to reduce any kind of bias at all bench. Although the researcher has taken utmost efforts to minimize such errors by cross-verification in the field of study.Since the study was limited in airline services and other state domestic airline service were not covered.

\section{Conclusion and Recommendations}

By doing a research on Airlines the chi square value that was obtained is 40.29 and the table value is 28.3 thus the null hypothesis is rejected and the alternative hypothesis is taken into consideration. Thus has been proved that aviation sector has superior services than any other sectors in India. After doing a study of this project representing on aviation sector, I have come to a conclusion that aviation industry is one of the largest and most widespread sector of the country providing its services not only in India as well as outside India also. The national carrier takes immense pride in having successfully played a pivotal role in making various facets of India popular with the people of the world and acting as the country's cultural ambassador. The airline uses the services of one of the advanced plans been operated in the world.

\section{References}

[1] Airport Authority of India, Traffic Data (http://www.aai.aero/traffic_news/annual_review.jsp), last accessed on 3rd October, 2009

[2] Ciliberto, Federico. 2008 "Strategic Deterrence in a Dynamic Game: Evidence from the Airline Industry."Unpublished.

[3] Conlon, Christopher T., and Julie Holland Mortimer. 2008. "Demand Estimation under Incomplete Product Availability." National Bureau of Economic Research Working Paper 14315.

[4] Dan Mahoney, Wesley W. WilsonChapter 11 The Size and Growth of Airports 3, 233-273.

[5] Gohain, K, "Airline Operations Regulatory Issues in India.

[6] Kumar, Nirmalya and Rogers Brian, 2000, easy Jet: The Web's Favourite Airline, Global Marketing, Business world Casebook.

[7] Krishnan, Rishikesha T, The Indian Airlines Industry in 2008, Case Study, IIM Bangalore,

[8] Kierulff, H. (2008). MIRR: A better measure. Business Horizons , 51, 321-329.

[9] International Journal of Applied Research and Studies (iJARS)

[10] ISSN: 2278-9480 Volume 3, Issue 3 (Mar - 2014)

[11] McFadden, Daniel. 1981. "Econometric Models of Probabilistic Choice." In Structural Analysis of Discrete Data with Econometric Applications, ed. Charles F. Manski and Daniel McFadden, 198-272. Cambridge, MA: MIT Press.

[12] Morrison, Steven A., Clifford Winston, Elizabeth E. Bailey, and Alfred E. Kahn. 1989. "Enhancing the Performance of the Deregulated Air Transportation System." Brookings Papers 